\title{
REPERCUSSÃO DA RELAÇÃO PROFESSOR-ALUNO NA FORMAÇÃO DE GRADUANDOS EM ENFERMAGEM
}

\author{
REPERCUSSION OF THE TEACHER-STUDENT \\ RELATIONSHIP IN UNDERGRADUATE \\ NURSING EDUCATION
}

\section{REPERCUSIÓN DE LA RELACIÓN PROFESOR-ALUMNO EN LA FORMACIÓN DE ESTUDIANTES DE ENFERMERÍA}

\author{
Larissa Merino de Mattos ${ }^{1}$ \\ Aline Marcelino Ramos ${ }^{2}$ \\ Edison Luiz Devos Barlem ${ }^{3}$ \\ Bárbara da Silva Gama ${ }^{1}$ \\ Alex Sandra Ávila Minasi ${ }^{4}$ \\ Caroline Bettanzos Amorim ${ }^{1}$
}

Como citar este artigo: Mattos LM, Ramos AM, Barlem ELD, Gama BS, Minasi ASÁ, Amorim CB. Repercussão da relação professor-aluno na formação de graduandos em enfermagem. Rev baiana enferm. 2019;33:e28274.

Objetivo: analisar a repercussão da relação professor-aluno na formação de graduandos em enfermagem. Método: estudo qualitativo, exploratório-descritivo, realizado com 27 estudantes do curso de graduação em enfermagem de uma universidade pública do Sul do Brasil. A coleta de dados ocorreu no mês de julho de 2017. Os dados foram analisados segundo a análise textual discursiva. Resultados: da análise dos dados, emergiram três categorias: "Barreiras na relação professor-aluno", "Facilitadores da relação professor-aluno" e "Ética nas relações professor-aluno". Conclusão: a repercussão da relação professor-aluno na formação de graduandos em enfermagem perpassa aspectos que contemplam não apenas o currículo acadêmico, mas também aspectos relacionais que determinam a forma de ser e agir dos futuros profissionais.

Descritores: Enfermagem. Educação em Enfermagem. Estudantes de Enfermagem. Docentes de Enfermagem. Ética.

Objective: analyze the repercussion of the teacher-student relationship in undergraduate nursing education. Method: qualitative, exploratory and descriptive study, involving 27 undergraduate nursing students at a public university in Southern Brazil. Data were collected in July 2017 Discursive textual analysis was applied to the data. Results: three categories emerged from the data analysis: "Barriers in the teacher-student relationship", "Facilitators of the teacher-student relationship" and "Ethics in the teacher-student relationships". Conclusion: the repercussion of the teacher-student relationship in undergraduate nursing education is fraught with aspects involving not only the academic curriculum, but also relational aspects that determine the future professionals' way of being and acting.

Descriptors: Nursing. Education, Nursing. Students, Nursing. Faculty, Nursing. Ethics.

\footnotetext{
Enfermeira. Pesquisadora independente. Rio Grande, Rio Grande do Sul, Brasil.merinolarissa@hotmail.com

Enfermeira. Mestre em Enfermagem. Rio Grande, Rio Grande do Sul, Brasil.

Enfermeiro. Doutor em Enfermagem. Professor do Programa de Pós-Graduação em Enfermagem. Universidade Federal do Rio Grande. Rio Grande, Rio Grande do Sul, Brasil.
}

Estudante de Enfermagem. Universidade Federal do Rio Grande. Rio Grande, Rio Grande do Sul, Brasil. 
Objetivo: analizar la repercusión de la relación profesor-alumno en la formación de estudiantes de enfermería. Método: estudio cualitativo, exploratorio-descriptivo, con 27 estudiantes de enfermería de una universidad pública del sur del Brasil. Recolección de datos en julio de 2017. Datos analizados según el análisis textual discursivo. Resultados: del análisis de datos, surgieron tres categorías: Barreras en la relación profesor-alumno, Facilitadores de la relación profesor-alumno y Ética en las relaciones profesor-alumno. Conclusión: la repercusión de la relación profesor-alumno en la formación de estudiantes de enfermería pasa por aspectos que contemplan no solo el curriculum académico, sino también aspectos relacionales que determinan la forma de ser y actuar de futuros profesionales.

Descriptores: Enfermería. Educación en Enfermería. Estudiantes de Enfermería. Docentes de Enfermería. Ética.

\section{Introdução}

Diante das transformações que vêm ocorrendo nos últimos tempos nas instituições de ensino superior, conduzidas principalmente pelas mudanças sociais que refletem diretamente no mundo do trabalho, verifica-se importante alteração no que diz respeito à matriz curricular dos estudantes de graduação. No caso dos estudantes de enfermagem, essa alteração diz respeito à necessidade de aumento da carga horária prática e maior articulação teórico-prática. Desse modo, a relação professor-aluno possui relevância quando se compreende a educação universitária como um lugar de interações sociais, onde sujeitos constroem juntos uma formação de profissionais pautada em princípios, valores, competências e atitudes ${ }^{(1)}$.

De acordo com as Diretrizes Curriculares Nacionais (DCN) do Curso de Graduação em Enfermagem, publicadas no ano de 2001, tem-se como objetivo formar enfermeiros generalistas, críticos e reflexivos, que sejam capazes de identificar e intervir nos problemas e nas situações de saúde e doença em seu local de trabalho. Além disso, o enfermeiro precisa ser capacitado e treinado para atuar com responsabilidade social e compromisso com a cidadania, promovendo a saúde integral do ser humano e cumprindo seu dever ético, conforme seu código de ética profissional $^{(2)}$. Para a construção mútua de conhecimentos, é necessário que o docente sinta-se disposto a participar do processo de interação, comunicação e troca de experiências com os acadêmicos. O acadêmico, por sua vez, deve participar de modo a contribuir com o docente e seus colegas, visando um efetivo método de ensino-aprendizagem ${ }^{(3)}$.

Nessa perspectiva, o vínculo entre docente e acadêmico consegue estabelecer conexões entre a realidade vivenciada dentro da universidade e a realidade vivenciada no mundo externo à universidade. Esse elo torna o ambiente acadêmico um local intensamente rico em saberes e conhecimentos, sendo essencial que os vínculos sejam pautados em confiança, respeito e afetividade, sempre em busca do equilíbrio, de modo que seja possível a orientação do docente ao acadêmico com o objetivo de auxiliar no crescimento pessoal e profissional ${ }^{(3)}$.

Por outro lado, é importante considerar que alguns métodos utilizados pelos docentes no ensino superior são limitados ou ultrapassados para ministrar aulas, podendo, assim, prejudicar a relação professor-aluno. Dessa forma, o discente, ao vivenciar uma prática pedagógica inadequada, pode sentir-se inibido de interagir e compartilhar a troca de experiências entre seus colegas e professores, o que poderia prejudicar as melhorias significativas na qualidade do ensino, bem como na capacidade crítica e reflexiva $^{(4)}$.

Portanto, a relação entre professor e aluno em um processo educativo deve ser baseada na confiança, afetividade e respeito. O docente tem a função de orientar o estudante para o seu crescimento pessoal e profissional e o discente, de participar ativamente em todos os momentos de interação dialógica ${ }^{(1)}$. Essa relação é representada como um fator que influencia nos aspectos relacionados ao aprendizado, em que o prazer 
de aprender é evidenciado no compromisso, na construção do conhecimento e no interesse demonstrado pelo aluno ${ }^{(5)}$.

A relevância deste estudo justifica-se pela importância de um bom relacionamento professor-aluno no ensino de enfermagem, dadas as implicações dessa interação na qualidade do aprendizado dos futuros enfermeiros envolvidos, bem como pela necessidade de abordagem dos desafios relacionados. A esses fatores acresce-se a escassez de pesquisas sobre a temática cujas implicações suscitam a necessidade de obtenção de uma visão mais profunda e abrangente na área.

Este estudo teve como objetivo analisar a repercussão da relação professor-aluno na formação de graduandos em enfermagem.

\section{Método}

Pesquisa qualitativa de cunho exploratório-descritivo, realizada em um curso de Graduação em Enfermagem de uma universidade pública do Sul do Brasil. Foram respondentes da pesquisa 27 estudantes de graduação em enfermagem, matriculados do primeiro ao nono semestre do curso. Os critérios de inclusão foram: ser estudante do curso de Graduação em Enfermagem, estar regularmente matriculado no semestre em que ocorreu a coleta de dados. Foram critérios de exclusão: estar em atestado ou licença durante o período de coleta de dados.

A coleta dos dados foi realizada por pesquisadores responsáveis, por meio de visitas às salas de aula das turmas referentes a cada semestre do curso, em horário previamente agendado com os professores e com o consentimento da coordenação do Curso de Graduação em Enfermagem da instituição de ensino superior em estudo. Nesses momentos, os coletadores, previamente treinados, apresentavam-se, informavam os objetivos do estudo e formalizavam o convite para participação. Destaca-se que foi estabelecido um número mínimo de três estudantes por semestre, totalizando 27 estudantes, de modo a resguardar a representatividade de cada série do curso.

As entrevistas semiestruturadas ocorreram no mês de julho de 2017. Foram gravadas com equipamentos de áudio, com duração média de 25 minutos, em salas de aula do curso pesquisado, reservadas para esse fim. O formulário de perguntas foi constituído por questões fechadas, para a caracterização dos participantes, como idade, sexo, ano de ingresso no curso, semestre atual; e questões abertas, com enfoque na repercussão da relação professor-aluno na formação dos estudantes de graduação em enfermagem, a exemplo de: Quais as fragilidades e potencialidades que você percebe no ensino do docente? Você considera a interação do aluno com o professor importante? Por quê? Você observou alguma situação (boa ou ruim) entre professor-aluno que lhe chamou atenção? Qual? $\mathrm{Na}$ sua percepção, os professores valorizam, incentivam seu aprendizado? O conhecimento compartilhado pelo professor é bem compreendido pelo aluno? Caso não seja, o professor busca outra didática para tentar fazer com que o aluno entenda?

Os dados foram submetidos à análise textual discursiva, metodologia de natureza qualitativa, que busca produzir novas compreensões acerca de fenômenos e discursos. Dessa forma, esse tipo de análise é constituído de três componentes fundamentais: a unitarização dos textos, o estabelecimento de relações e a captação do novo emergente. Durante a análise e a categorização, foram identificadas diferentes unidades de significados. Foi possível agrupá-las com base nos significados mais próximos para obter-se as unidades de sentido e as categorias finais ${ }^{(6)}$.

Como mostra o Quadro 1, emergiram três categorias, de acordo com o objetivo do estudo: 
Quadro 1 - Modelo estrutural de construção das categorias.

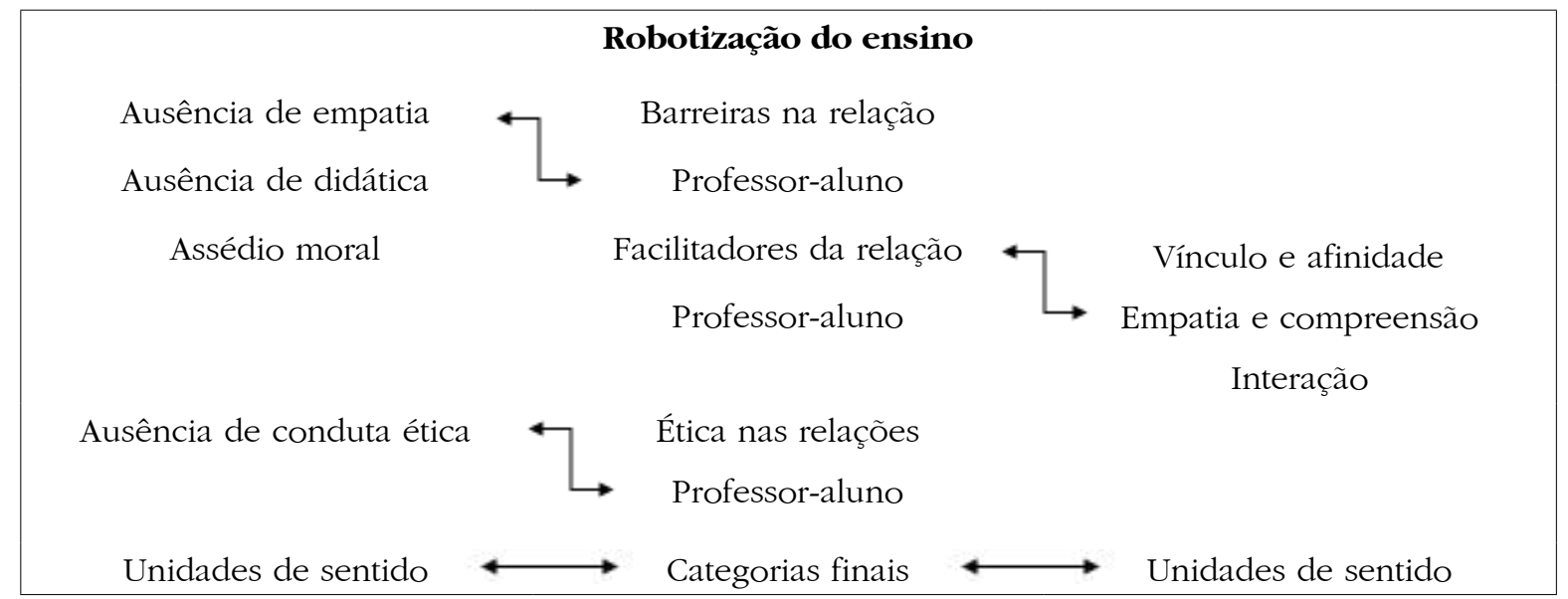

Fonte: Elaboração própria.

Este estudo, cumpriu o recomendado pela Resolução nº 466/2012 da Comissão Nacional de Ética em Pesquisa, Ministério da Saúde, sobre pesquisa envolvendo seres humanos. Foi aprovado pelo comitê de ética local sob parecer $\mathrm{n}^{\mathrm{o}}$ 63/2017. Para assegurar os princípios éticos, os alunos que aceitaram participar voluntariamente da pesquisa assinaram o Termo de Consentimento Livre e Esclarecido (TCLE) em duas vias, das quais uma ficou em seu poder. Para preservar a identidade dos estudantes, eles foram identificados pela letra E (Estudante), seguida do número indicativo da ordem da entrevista, da letra $\mathrm{S}$ (semestre) e de um número que indicava a série que estavam cursando (por exemplo: E1S1, E2S1.

\section{Resultados e Discussão}

A caracterização dos 27 estudantes de graduação em enfermagem entrevistados evidenciou que 25 eram mulheres, a faixa etária variou entre 18 e 41 anos, 21 eram solteiros, apenas 5 tinham filhos e 15 possuíam algum tipo de atividade extracurricular na graduação. Dados semelhantes foram verificados em outros estudos, cujo número de estudantes de graduação em enfermagem representado por mulheres, compreendeu cerca de $70 \%$ dessa população. Sendo assim, o fato de as mulheres serem mais preocupadas com as questões de saúde pode estar associado com a procura pelo curso $^{(7)}$.
Outro dado importante refere-se ao predomínio de estudantes solteiros, que pode ser melhor compreendido pelo reflexo da própria realidade brasileira, cuja população estudantil tem optado por priorizar a formação profissional e a inserção no mercado de trabalho para posteriormente direcionar a atenção para aspectos conjugais $^{(7)}$.

$\mathrm{Na}$ análise dos dados, emergiram três categorias relacionadas com o objetivo do estudo: "Barreiras na relação professor-aluno", "Facilitadores da relação professor-aluno" e "Ética nas relações professor-aluno".

\section{Barreiras na Relação Professor-Aluno}

Foi possível identificar como principais fragilidades: a banalização, a rotina de ensino e a relação de poder de docente sobre discentes. Estas barreiras são prejudiciais na relação do professor com o aluno, uma vez que a falta de atividades dinâmicas bloqueia as ações dos estudantes frente às atividades teórico-práticas, além de gerar conflitos, como descrito nas falas:

\footnotetext{
Alguns professores passam uma ideia de ensino centralizado. O que ele fala é regra e ponto. Ele não dá muito espaço para mudança, não se torna muito dinâmico. Então, às vezes, acontece alguns conflitos entre o professor-aluno em consequência disso. (E22S9).

Tem professores que não estão abertos a nada. A gente coloca qualquer coisa, e eles não aceitam. Tem que ser da forma deles, tanto nos estágios como nas aulas teóricas, e isso, muitas vezes, dificulta a relação professor-aluno. (E24S8).
} 
Em consonância com esses achados, estudo internacional realizado com 16 estudantes de enfermagem identificou que a instabilidade e a falta de apoio identificada nas relações professor-aluno, podem influenciar de forma negativa na formação clínica dos futuros profissionais. Além disso, os estudantes participantes acreditavam que a falta de apoio e a nítida relação de superioridade dos educadores reduziria sua vontade de aprender e buscar novos conhecimentos ${ }^{(8)}$.

A carreira docente evidencia a necessidade de o professor atuar em múltiplas funções, sendo interlocutor, orientador e educador, pois este é o principal ator e meio de comunicação direta do seu aluno no ensino-aprendizagem. Dessa forma, para que possa ocorrer uma mudança na qualidade do ensino, os docentes precisam refletir sobre sua visão no tocante à educação, entender o significado e, consequentemente, buscar melhorar o processo de ensino, analisando todas as possibilidades dentro de sua prática docente ${ }^{(9)}$. Além disso, a formação profissional necessita ser entendida como um processo de construção e de organização pedagógica, de forma a articular a didática de maneira mais criativa e dinâmica em consonância com as novas realidades ${ }^{(10)}$.

Entretanto, a sobrecarga de atividades sob a responsabilidade do professor pode comprometer ou prejudicar o aprendizado do aluno, devido à mecanização, que facilita diminuir o tempo necessário para efetuar os compromissos diários do docente. Dessa forma, é necessário refletir, discutir e problematizar, para que o profissional consiga visualizar suas potencialidades e seus limites e possa promover uma mudança efetiva no cuidado de enfermagem para com seus alunos. Desse modo, poderá eliminar a prática e o pensamento robotizado do ensino, facilitar a interação professor-aluno e consequentemente diminuir o impacto negativo que isso pode acarretar $^{(11)}$.

A ausência de empatia do professor com o aluno também é mencionada nas falas dos estudantes, como fator que dificulta o processo de ensino-aprendizagem e até mesmo desestimula o aluno, quanto aos seus objetivos e metas durante a graduação. Quando questionados sobre a flexibilidade no ensino para melhor aprendizado do aluno, eles responderam:

O professor simplesmente chegou na sala de aula e disse
que tinha adiantado um mês a nossa apresentação de
seminário. Tivemos que modificar tudo que haviamos
planejado; isso foi muito ruim. (E8s6).

Eles só se preocupam em passar os conteúdos. Não buscam saber sobre as dificuldades que os alunos apresentam fora da universidade, pensam que o aluno só vive naquele mundo. Falta um pouco de empatia para compreender determinadas atitudes. (E7S3).

Nesse sentido, o significado da importância da dedicação, empatia e qualidade dos cuidados deve ser parte integrante de discussões acadêmicas durante a graduação, pois apresenta um avanço para melhorias nas disciplinas do curso e, assim, afeta positivamente a qualidade do cuidado de si e do outro ${ }^{(11)}$. É necessário que a equipe docente seja responsável por atender a individualidade de cada aluno, de forma a suprir as necessidades emergenciais que prejudiquem o desenvolvimento acadêmico. Com isso, o compromisso e o respeito, tanto pelos discentes quanto pelos docentes, torna-se essencial, uma vez que, para que se tenha sucesso no processo de ensino, ambos precisam participar e se respeitar mutuamente ${ }^{(12)}$.

A ausência de didática do professor em determinados momentos é citada pelos estudantes como fator que reflete diretamente no aprendizado e no impacto que pode gerar na relação de ambos:

Alguns professores atuam mecanicamente, falam, falam, leem os slides e perguntam: Alguém tem alguma dúvida? Ai tu perguntas, ele te responde a mesma coisa que falou nos slides, sem nenhum exemplo prático. (E9S4).

Claro que existem suas exceções. Não dá para generalizar, porque tem gente muito boa nos dando aula, que não teve prática, mas, primeiro de tudo, que tenham pelo menos um tempinho na parte assistencial, para ver como é a rotina. Porque, às vezes, eles saem da graduação, vão para o mestrado, doutorado, pós-doutorado e vem dar aula, nos trazendo a possibilidade de realização de procedimentos perfeitos, com todos os equipamentos que tu sonhas e, ao se deparar com a realidade prática, não tem nada. Acho que deveriam, pelo menos, vincular mais com a realidade, ter mais bagagem. (E22S7).

Embora cada professor tenha sua maneira de ministrar aula, é necessário enfatizar a importância de buscar o aperfeiçoamento e a atualização, para que esteja sempre renovando e 
levando informações novas aos alunos, o que também concorre para seu próprio crescimento profissional $^{(9)}$. Alguns aspectos foram enfatizados pelos participantes da pesquisa, como: falta de fundamentação teórica, para usar como base para a educação de cuidados no âmbito de prática; falta de metodologias eficazes para educação em enfermagem; uso de métodos tradicionais, como a teoria e a exposição, considerados desatualizados ${ }^{(13)}$.

Assim, torna-se necessário ampliar as reflexões sobre o processo de ensino-aprendizagem tanto do docente quanto do discente, além de valorizar os aspectos positivos e negativos encontrados em suas práticas cotidianas, a fim de promover processos de mudanças e melhorias. É também indispensável o investimento do docente em constantes atualizações didáticas e na área de formação ${ }^{(14-15)}$.

\section{Facilitadores da Relação Professor-Aluno}

Nesta categoria, observou-se o vínculo e a afinidade do professor com o aluno, além de métodos didáticos facilitadores da interação. Em consonância com esses achados, identificou-se que, quando estabelecida uma boa relação professor-aluno, o discente passava a demonstrar mais interesse pela disciplina, tornando a aula tranquila e agradável, ao mesmo tempo que demonstrava confiança e comprometimento com a profissão escolhida. Dessa forma, foram-se modificando a maneira de agir e de se relacionar com os discentes, reduzindo o distanciamento gerado entre um e outro por qualquer motivo ${ }^{(16)}$.

Observa-se, quando as relações são criadas e mantidas, que há um processo de companheirismo entre professores e alunos, fortalecendo o vínculo e suspendendo a figura do ser superior que os discentes criam e dissipam pela instituição de ensino, estabelecendo uma conexão de troca de conhecimento ${ }^{(16)}$. Ao serem questionados sobre as potencialidades identificadas no processo de ensino-aprendizagem, os participantes responderam:

Eu acho que o professor que te dá autonomia, e que demonstra confiança em ti, que valorizam o teu fazer e a tua iniciativa, contribuem para a formação do aluno. Portanto, eu acho que é uma potencialidade, um facilitador. (E23S9).

Por mais que pareça boba a pergunta, para determinada professora não existem perguntas bobas, mesmo que chegue no fim da aula e tu levante a mão para dizer: não entendi nada. Ela vai perguntar "o que tu não entendeu?" E explica tudo de novo. Existe uma vontade de ensinar. Então, isso é uma relação positiva e é uma interação que motiva a pessoa a continuar dentro de uma faculdade. (E15S1).

A última fala demonstra um modelo de docente que torna a aula mais atrativa, conduzindo o ensino com mais abertura para perguntas e respostas, incentivando os alunos a aprenderem de forma dinâmica, sem repressão ao questionar o docente. De forma semelhante, em uma pesquisa realizada numa faculdade de medicina no interior de São Paulo, a relação professor-aluno é destacada como um encontro pedagógico que permite a experiência subjetiva necessária ao aprendizado da competência profissional. Nesse caso, os estudantes valorizavam o vínculo com o professor, especialmente quando se sentiam acolhidos, sentindo essas experiências como fundamentais para o seu desenvolvimento educacional $^{(17)}$.

Ademais, ao ingressarem em uma universidade, os estudantes passam por variados processos de mudanças, com adaptações constantes que, dependendo da forma como são realizadas, podem resultar em processos negativos em suas vidas e isolamento social. Esses aspectos podem dificultar o relacionamento com o docente, no que tange à afinidade e ao vínculo, e também o relacionamento com os pacientes, resultado do desinteresse pelo treinamento profissional, que é o pilar e a base do curso de graduação em enfermagem $^{(18)}$.

Em estudo sobre determinantes da satisfação acadêmica, realizado com graduandos de enfermagem no extremo Sul do Brasil, identificou-se que os acadêmicos, quando satisfeitos com a relação com os professores e a instituição de ensino, sentiam-se motivados e mais envolvidos com as atividades do curso, o que interferia positivamente no aproveitamento do aprendizado e na competência do futuro profissional ${ }^{(19)}$. 
O vínculo entre professor-aluno é importante quando estabelece a confiança e o respeito no processo de ensino, amenizando o impacto das experiências realizadas em ambientes hostis. Sendo assim, o professor que busca entender as dificuldades dos alunos, proporciona de forma global melhor aprendizado, facilita a compreensão e consequentemente a interação em âmbito pessoal e profissional ${ }^{(20)}$. As falas a seguir são ilustrativas:

\begin{abstract}
Nesse semestre, não estava sendo legal a distribuição das aulas práticas assistenciais, e a professora mudou o sistema, para que a gente pudesse desenvolver o raciocinio clínico, já que não estávamos conseguindo, devido à quantidade de procedimentos técnicos que tínhamos que realizar, indo de encontro ao objetivo da disciplina. E então, ela tentou mudar, e isso foi bem legal da parte dela. Ela aceitou nossa sugestão, porque nós falamos que estávamos com dificuldade, e ela modificou a metodologia, para que conseguíssemos desenvolver esse raciocínio. (E8S6).

A afinidade com o professor reflete na própria prática de ensino, porque tu consegue fazer os questionamentos necessários de uma forma tranquila. Às vezes, o aluno deixa de perguntar e erra, justamente por ter medo de perguntar para o professor... justamente porque ele não tem uma relação boa, isso com certeza afeta no dia a dia do aluno. (E4S5).
\end{abstract}

A falas confirmam que a relação entre professor e aluno é valorizada quando regada pelo diálogo e respeito entre ambos, pois ninguém educa a si mesmo. A compreensão de que uns precisam dos outros é notória na área da saúde, principalmente na educação e na formação acadêmica. A valorização do professor e as constantes trocas de experiências e saberes reflete-se durante as aulas e no ato de ensinar, tornando o docente um facilitador da aprendizagem ${ }^{(2)}$.

$\mathrm{Na}$ área da saúde, os profissionais não devem empregar somente a técnica; é preciso atentar para as ações sobre o outro e para o outro, com responsabilidade ética e crítica. Assim, toda e qualquer prática realizada pelo profissional tem como essência a interação e as relações de comunicação, pois a profissão é relacionada com a empatia e todas as suas ações repercutem no próximo ${ }^{(21)}$.

Além disso, situações que envolvem estágio supervisionado em campo hospitalar sinalizam um período por vezes amedrontador para os alunos, que esperam uma atitude mais flexível do docente, ao lidar e conhecer cada uma de suas potencialidades e limitações. Se isso não ocorre, sentem-se insatisfeitos e desmotivados, passando a perceber o docente como uma ameaça. Desse modo, o campo prático gera insegurança e medo nos alunos, pois, muitas vezes, são repreendidos pelos docentes na frente do paciente. Esta circunstância também não diverge da insegurança que apresentam no momento de realizar provas práticas em laboratório e até mesmo em seus questionamentos em sala de aula $^{(22)}$.

Nessa perspectiva, uma experiência positiva entre professores e alunos é percebida quando cada um possui um entendimento compartilhado do outro. Quando o professor é motivador, respeitoso, gentil e confiável com os alunos, e consegue reduzir, de forma efetiva, os níveis de ansiedade deles durante as atividades práticas. Isso demonstra que um relacionamento eficaz ajuda a modificar o comportamento do aluno, de modo a garantir resultados positivos no processo de aprendizagem ${ }^{(23)}$.

\section{Ética nas Relações Professor-Aluno}

Nessa categoria são evidenciadas as relações éticas estabelecidas nos campos didáticos, práticos e nos estágios. Foi possível identificar a percepção de que, durante a graduação de enfermagem, não somente o conhecimento técnico e teórico precisa ser abordado, mas a formação ética do caráter de cada futuro profissional é também uma responsabilidade do educador que, nesse aspecto, desempenha o papel fundamental $^{(21)}$. Assim, é necessário disseminar o conhecimento de um ensino reflexivo, com o objetivo de desafiar e estimular os alunos na construção de habilidades e competências que fortaleçam o compromisso profissional de cada aluno $^{(24)}$.

Ao serem questionados sobre possíveis situações ruins entre professor/aluno nas atividades de ensino, chamaram a atenção os seguintes acontecimentos:

Acho ruim, quando o professor chama a atenção do aluno na frente do paciente em atividades práticas 
assistenciais. Acredito que, se o aluno irá colocar o paciente em risco, o professor deve chamá-lo para conversar sobre a situação, mas eu acho horrivel quando o aluno é corrigido na frente do paciente, porque o paciente já demonstra insegurança ao saber que somos acadêmicos. Uns deixam a gente realizar procedimentos, outros ficam mais receosos e ainda o professor vai chamar atenção na frente do paciente, para o aluno fica muito complicado. (E24S9).

Situações como, por exemplo, o professor dizer que podemos contar com ele, que é para falarmos o que sentimos, nossas inseguranças no campo prático, os procedimentos que temos medo de realizar e depois ficar sabendo que o professor falou para outro professor, ou outro profissional da unidade do hospital em que estamos atuando como estagiários, o que na verdade são nossas fragilidades $e$ medos interiores que foram confiados ao professor na tentativa de um apoio, e não o contrário, do professor nos envergonhar ou causar algum constrangimento, sem empatia nenbuma. (E4S6).

Já ouvi professores comentando com outros alunos que o aluno " $x$ " fez isso de errado, expondo toda a situação. Não é nada ético expor um aluno assim; me senti bem mal. (E3S4).

Em estudo realizado com 30 profissionais de saúde em unidades de internação de um hospital universitário, obteve-se como resultado o relato de problemas éticos apontados pelos próprios profissionais. Então, considerou-se que o cuidado hospitalar tem sido realizado por meio de ações totalmente mecanizadas, sem nenhum tipo de envolvimento e empatia. Quando os profissionais estão inseridos na prática, a atitude de preocupação, empatia, interação com a equipe, com o outro e os aspectos mais subjetivos das relações humanas podem ficar ocultos ${ }^{(21)}$. Assim, independente do semestre em que se encontram os acadêmicos, a inserção no campo de atuação prática, nos variados cenários de saúde, trazem consigo a realização de técnicas e procedimentos que, por si só, geram medo e insegurança, além de situações antiéticas que podem estar imbricadas nesses locais, o que intensifica a necessidade de empatia pelo profissional docente.

Essas percepções corroboram outro estudo brasileiro, realizado com a equipe de enfermagem em um hospital universitário, que também evidenciou que a exposição das informações por profissionais da área da saúde tem se tornado uma prática antiética ${ }^{(21)}$.

Compreender as próprias atitudes para identificar postura ética torna-se essencial para espelhar qualidade de ensino e qualidade profissional.
Assim, é necessário que pontos positivos sejam ressaltados e negativos sejam repreendidos $\mathrm{e}$ discutidos, pois os alunos que os docentes estão formando, possivelmente serão os profissionais que irão estar no mercado de trabalho. Estes, por sua vez, reproduzirão as práticas vivenciadas durante a formação acadêmica ${ }^{(19)}$.

Vale ressaltar que o ensino da ética, na formação profissional dos estudantes de graduação, busca refletir sobre comportamento humano, interpretar, discutir, problematizar e definir valores e princípios. A maior parte das fragilidades apresentadas por profissionais ou até mesmo acadêmicos de enfermagem serve de ensino para a aprendizagem, pois possibilita a observação e a reflexão acerca de problemas éticos existentes no cotidiano de trabalho, além de buscar a mudança para alcançar o sucesso e corrigir o erro ${ }^{(15)}$.

Devido a tal problemática, o curso de graduação em enfermagem vem passando por mudanças ao longo do tempo, fomentadas pelas novas diretrizes curriculares nacionais. Estas, enfatizam a melhoria das propostas pedagógicas, com o propósito de ir em busca de atualidades, habilidades de liderança, conhecimento para a tomada de decisões amparada pela ética e capacidade de identificação e resoluções dos problemas. Busca-se, por meio do raciocínio crítico e reflexivo, a autonomia, a comunicação e a aproximação entre teoria e prática ${ }^{(15)}$.

Desse modo, a formação profissional do enfermeiro deve concentrar-se não apenas em habilidades técnicas, mas direcionar-se para o desenvolvimento do conhecimento adquirido, a variedade de experiências e vivências da ética e o fortalecimento da construção e consolidação da vida profissional ${ }^{(15)}$.

O estudo foi realizado em uma população específica, o que se torna uma limitação.

\section{Conclusão}

Diversas situações podem determinar a percepção global de estudantes acerca da qualidade de um curso de graduação e de sua formação, em especial quando se trata da relação com os docentes de um curso de graduação em 
enfermagem, a didática desenvolvida por esses, a empatia, a dinamicidade e a habilidade pedagógica em troca de experiências e conhecimentos teóricos e práticos essenciais à futura profissão. O medo de questionar o docente tem um impacto negativo no desenvolvimento e na aprendizagem dos alunos, pois limita sua evolução no ensino e aprendizado, independente do semestre em que se encontre.

Torna-se fundamental que o docente exerça sua atuação diante de um compromisso ético com alunos e colegas de profissão, desenvolvendo atividades dinâmicas para o compartilhamento de conhecimentos, de modo a realizar e favorecer a troca de experiências para o enriquecimento de vivências, o que permitirá fortalecer a construção e a consolidação do profissional que está sendo formado. Além disso, identificar os problemas e os desafios da educação em graduação de enfermagem, especialmente os fatores relacionais, facilita o processo de formação e melhora a qualidade profissional dos futuros enfermeiros.

Conclui-se que a repercussão da relação professor-aluno na formação de graduandos em enfermagem perpassa aspectos que contemplam não apenas o currículo acadêmico, mas também aspectos relacionais que determinam a forma de ser e agir dos futuros profissionais.

Sugere-se que o tema seja explorado nos cursos de graduação em enfermagem de outras instituições do país e em outros cursos de graduação.

\section{Colaborações:}

1. concepção, projeto, análise e interpretação dos dados: Larissa Merino de Mattos, Aline Marcelino Ramos, Edison Luiz Devos Barlem, Bárbara da Silva Gama,Alex Sandra Ávila Minasi e Caroline Bettanzos Amorim;

2. redação do artigo e revisão crítica relevante do conteúdo intelectual: Larissa Merino de Mattos, Aline Marcelino Ramos e Edison Luiz Devos Barlem;
3. aprovação final da versão a ser publicada: Aline Marcelino Ramos e Edison Luiz Devos Barlem.

\section{Referências}

1. Rodrigues JDA, Rocha LDS, Anjos DSD, Cavalcante LPF, Rozendo CA. Pedagogical trends: conflicts, challenges and perspectives of nursing teachers. Rev bras educ med. 2013;37(3):333-42.

2. Brasil. Ministério da Educação. Resolução CNE/ CES n. 3, de 7 de novembro de 2001. Institui Diretrizes Curriculares Nacionais do Curso de Graduação em Enfermagem. Brasília; 2001.

3. Albuquerque C. Processo ensino-aprendizagem: características do professor eficaz. Millenium-J Educ Technol Health. 2016;(39):55-71.

4. Houseal AK, Abd-El-Khalick F, Destefano L. Impact of a student-teacher-scientist partnership on students' and teachers' content knowledge, attitudes toward science, and pedagogical practices. J Res Sci Teach. 2014 Jan;51(1):84-115.

5. Gonçalves ASR, Pires DEP. The work of college health sciences faculty: situations that cause pleasure and pain. Rev Enferm UERJ. 2015;23(2):266-71.

6. Moraes R, Galiazzi MC. Análise textual discursiva. 2a ed. rev. Ijuí: Unijuí; 2011.

7. Moura IH, Nobre RS, Cortez RMA, Campelo V, Macedo SF, Silva ARV. Qualidade de vida de estudantes de graduação em enfermagem. Rev Gaúcha Enferm [Internet]. 2016 jun [cited 2018 Jul 3];37(2):e55291. Available from: http://www.scielo.br/scielo.php?pid=S1983$14472016000200407 \&$ script=sci_arttext

8. Bazrafkan L, Kalyani MN. Experiencias de la práctica clínica de los estudiantes de enfermería: un estudio cualitativo. Invest Educ Enferm [Internet]. 2018 [cited 2018 Jun 14];36(3):e04. Available from: http://www.scielo.org.co/scielo.php?script=sci_ arttext\&pid=S0120-53072018000300004

9. Lima VC. As tecnologias da informação e da comunicação no processo educativo. RELECS. 2017;1(1):106-16.

10. Bolzan DPV, Isaia SMA, Maciel AMR. Formação de professores: a construção da docência e da atividade pedagógica na Educação Superior. Rev Diálogo Educ. 2013;13(38):49-68. 
11. Ardigo FS, Amante LN. Knowledge of the professional about nursing care of people with ostomies and their families. Texto contexto enferm. 2013 out/dez;22(4):1064-71.

12. Oliveira JLC, Papa MAF, Wisniewki D, Inoue KC, Costa MAR, Matsuda LM. Quality of care: concepts from nursing students. Rev Min Enferm. 2015;19(1):30-42.

13. Coelho MP, Menezes HF, Rosas AMMTF, Rosa AF, Pinto ACS, Saraiva RJ. Teaching in nursing care of undergraduate courses in brazil: integrative review. J Nurs UFPE on line. 2016 [cited 2018 Jun 16];10(2):647-56. Available from: https://pdfs.semanticscholar.org/14dd/e4669 644513b254422d96273fa7a7fef2590.pdf

14. Acioli S, Correia LM, Souza NVDDO, Pereira ALF, Ferraccioli P, Ferreira VDA. Evaluation of the educational process in nursing undergraduate courses. Rev Enferm UERJ. 2014;22(6):801-7.

15. Bordignnon SS, Escobal APL, Garcia B, Meincke SMK, Soares MC, Thofhern MB. Produção científica acerca do ensino da ética na enfermagem. J Nurs Health. 2015;5(1):55-67.

16. Junges KS, Behrens MA. Uma formação pedagógica inovadora como caminho para a construção de saberes docentes no Ensino Superior. Educ Rev. 2016;32(59):211-29.

17. Pio DAM, Bocchi SCM, Vieira CM, Chirelli MQ. A reciprocidade na relação professor-estudante em um curso médico que utiliza métodos ativos. Rev Eletrônica Educ. 2019 maio/ago;13(2):619-31. DOI: http://dx.doi.org/10.14244/198271992506

18. Bordignon SS, Lunardi VL, Barlem ELD, Lunardi FWD, Tomaschewski-Barlem JG, Ramos AM. Moral distress among undergraduate nursing students who question the choice of professional career. J Nurs Socioe Health. 2014;1(1):63-9.

19. Ramos AM, Tomaschewski-Barlem JG, Lunardi VL, Barlem ELD, Silveira RS, Bordignon SS. Satisfação com a experiência acadêmica entre estudantes de graduação em Enfermagem. Texto Contexto Enferm. 2015;24(1):187-95.

20. Almeida EM. A relação professor-aluno: intervenientes na construção da identidade profissional. Qualis Sumaré-Rev Acad Eletrôn. 2016;(1):75-85.

21. Montenegro LC, Rénno HMS, Caram CS, Brito MJM. Problemas éticos na prática de profissionais de saúde em um hospital escola. Av. Enferm. 2016;34(3):226-35.

22. Ramos AM, Tomaschewski-Barlem JG, Lunardi VL, Barlem ELD, Schmidt LG, Dalle Nogario AC. Determinantes da satisfação com a experiência acadêmica entre estudantes de graduação em enfermagem. Rev Enferm UERJ [Internet]. 2016 [cited 2018 May 23];24(4):e9555. Available from: https://www.redalyc.org/pdf/714/71438421023. pdf

23. Rojas Reyes J, Rivera Álvarez LN, Morera Pomarede MJ. Pedagogic Aspects in Nursing Education: Integrative Review. Invest Educ Enferm [Internet]. 2018 [cited 2018 Feb 4];36(3):e03. Available from: http://www.scielo.org.co/scielo.php?script=sci arttext\&pid=S0120-53072018000300003

24. Amorim LM, Patriota NSP, Barbosa VFB, Oliveira VL, Henriques AHB. Desafios no processo de ensino e aprendizagem: estudo sob a ótica docente de curso de graduação. REBES, 2016;6(2):13-20.

Recebido: 30 de setembro de 2018

Aprovado: 19 de agosto de 2019

Publicado: 13 de novembro de 2019

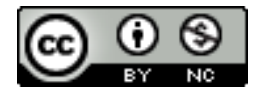

A Revista Baiana de Enfermagem utiliza a Licença Creative Commons - Atribuição-NãoComercial 4.0 Internacional. https://creativecommons.org/licenses/by-nc/4.0/ Este artigo é de acesso aberto distribuído sob os termos da Licença Creative Commons (CC BY-NC). Esta licença permite que outros remixem, adaptem e criem a partir do seu trabalho para fins não comerciais. Embora os novos trabalhos tenham de lhe atribuir o devido crédito e não possam ser usados para fins comerciais, os usuários não têm de licenciar esses trabalhos derivados sob os mesmos termos. 